\section{Wide neck bifurcation aneurysms: what is the optimal
endovascular treatment?}

Wide neck bifurcation aneurysms (WNBAs) are among the most difficult saccular aneurysms (with large and giant aneurysms) to treat by a surgical or endovascular approach. ${ }^{1}$ Since aneurysm coiling was introduced, endovascular treatment (EVT) of WNBAs has been challenging for several reasons: (1) neck width makes it difficult to stabilize coils in the aneurysm sac and there is an associated risk of coil protrusion and thromboembolic complication; (2) WNBAs frequently have one to several branches arising from the neck, which may lead to branch occlusion during coiling; and (3) wide neck is associated with a higher risk of aneurysm recanalization. ${ }^{2}$ To overcome these challenges, several options have been successively developed: balloon assisted coiling (BAC, also known as remodeling technique), stent assisted coiling (SAC), flow diversion, and intrasaccular flow disruption. $^{3}$

Comparative evaluation of these techniques is complicated by the great variety of aneurysm morphology and lack of a homogeneous indication system for selecting one or another in a specific case. Therefore, creating a safety and efficacy hierarchy between these different techniques requires a scientifically sound evaluation of the individual technique results to determine its specific place in the armamentarium of tools available for EVT of WNBA. This evidence based approach is particularly critical during the COVID-19 pandemic, which forces practitioners to rely on digital techniques to share knowledge and experience. As the possibility of debate is limited in this increasingly digital environment, there is a clear risk of clinicians deliberately misrepresenting studies and results while reporting their beliefs to be scientifically proven to the interventional neuroradiology community. More than anything, it is vital that we avoid disseminating 'fake news' in the interventional neuroradiology field.

BAC was evaluated in several series and primarily showed a similar safety compared with coiling alone, but no real improvement to anatomical results. ${ }^{4}$ This technique still has a place in the management of ruptured WNBAs at the acute phase of bleeding as some other techniques (SAC and flow diversion) are contraindicated (or not indicated) in this setting due to the requirement for dual antiplatelet treatment (DAPT). Also, if BAC is usually performed (singularly for sidewall aneurysms) with a single balloon technique, it is sometimes necessary for WNBA treatment to use a double balloon technique, which makes the procedure slightly more complicated technically. ${ }^{45}$

SAC was introduced almost 20 years ago and has been evaluated in numerous retrospective and prospective single and multicenter series. ${ }^{6}$ Most studies investigated all types of aneurysms, including unruptured and ruptured (see below) and narrow and wide neck aneurysms (WNAs). However, in some studies, only WNAs were included, or a subgroup analysis was conducted in WNAs. ${ }^{7-10}$ In the WNA subgroup of the Matrix and Platinum Science (MAPS) trial, the rate of periprocedural adverse events was similar in the SAC (6.6\%) and coiling (4.5\%) groups, while the rate of stroke within 1 year of treatment was higher in the SAC $(8.8 \%)$ than in coiling group $(2.2 \%) .^{7}$ Similarly, in a multicenter, prospective study conducted in the USA and dedicated to WNA located in the anterior circulation treated with SAC (using a laser cut stent), the rate of major adverse events (major ipsilateral stroke or neurological death) was $4.4 \% .^{10}$ A similar percentage (5.2\%) was reported in a recent multicenter, prospective trial evaluating a braided stent. ${ }^{9}$ Finally, in a recent meta-analysis evaluating one of the most recently developed stents, complication rates in the WNA subgroup were relatively similar to those reported in MAPS $(6 \%){ }^{8}$

With regard to SAC efficacy, the MAPS trial showed rates for complete aneurysm and adequate (complete occlusion and neck remnant) occlusion in the WNA subgroup of $45.7 \%$ and $62.8 \%$, respectively. ${ }^{7}$ In the USA trial (laser cut stent), complete and adequate occlusions were obtained at 12 months in $88.2 \%$ and $96.1 \%$, respectively. ${ }^{10}$ In the USA trial, dedicated to the braided stent, complete and near complete $(\geq 95 \%)$ aneurysm occlusion rates at 12 months were reported as 70.6\% and 92.1\%, respectively. ${ }^{9}$ Similar results were reported in the recent meta-analysis, with $88 \%$ and $93 \%$ adequate occlusion at 6 and 12 months, respectively. ${ }^{8}$

In contrast with MAPS and the USA series studying laser cut and braided stents, the meta-analysis mixed ruptured and unruptured aneurysms, but the use of SAC in ruptured aneurysms remains controversial due to the requirement for DAPT. ${ }^{8}$ In a meta-analysis comparing SAC and coiling alone in ruptured aneurysms, the rate of perioperative complications was higher in the SAC group (20.2\%) compared with the coiling group (13.1\%). ${ }^{11}$ In the SAC group, rates of hemorrhagic and ischemic complications were higher compared with the coiling group; however, the rate of aneurysm re-rupture was not analyzed. While one stent is sometimes sufficient to cover the neck of a bifurcation aneurysm, in other cases a two stent technique is occasionally necessary ( $\mathrm{Y}$ stenting is most commonly used). In a recent metaanalysis, treatment related complications, and morbidity and mortality rates were $8.9 \%, 2.4 \%$, and $1.1 \%$, respectively. ${ }^{12}$ In the long term, complete/near complete aneurysm occlusion (close from adequate occlusion) was $95.4 \%$.

The use of flow diversion for the treatment of bifurcation aneurysms was initially controversial for two main reasons: (1) covering one or several branches of the bifurcation was considered dangerous given the risk of occlusion; and (2) since two flow diverters cannot be placed in the bifurcation, a potential risk of incomplete coverage of the aneurysm neck leading to incomplete aneurysm occlusion exists. Initial experience was disappointing, with a relatively high morbidity rate $(22 \%)$ and a relatively low rate of complete aneurysm occlusion (62\%). ${ }^{13}$ However, the development of lower profile flow diverters, better understanding of the anatomy and related indications, and the improved clinician skills led to safety and efficacy improvement with this technique. In a relatively small series of patients with bifurcation aneurysms treated by flow diversion, Michelozzi et al reported a morbidity rate of $3.4 \%$ and mortality rate of $0.0 \% .{ }^{14}$ The rate of complete aneurysm occlusion was $82.1 \%$ at 12 months. With regard to covered branches of the bifurcation, $20.0 \%$ were occluded, 51.4\% had a reduced caliber, and $28.5 \%$ were unchanged. The use of DAPT to prevent intrastent thrombosis limits the indications of flow diversion to unruptured aneurysms, with the exception of blister aneurysms that are usually difficult to treat with any other technique.

The Woven EndoBridge (WEB) device was initially developed for the treatment of WNBAs. In parallel with its technical development (dual layer to single layer, enhanced visualization, reduction in size of the delivering microcatheter), ambitious clinical evaluations were conducted in Europe (WEB Clinical Assessment of Intrasaccular Aneurysm Therapy (WEBCAST) and WEBCAST-2), in the USA (WEB Intra-saccular Therapy (WEB-IT)), and in France (French Observatory). In contrast with typical clinical evaluation in the interventional neuroradiology field, evaluation 
in these studies began soon after the introduction of the device into clinical practice. All WEB studies conducted, analyzed, and published to date have shown similar good results in terms of safety: no mortality in the WEB-IT and the combined population of European and France studies, and low morbidity at 1 month $(0.7 \%$ in WEB-IT and $3.0 \%$ in European and French studies, with $1.2 \%$ procedure related morbidity). ${ }^{15-17}$ In a recent multicenter study conducted in the USA to evaluate WEB in ruptured aneurysms, similar results were reported, with $0.0 \%$ and $3.3 \%$ procedure related mortality and morbidity, respectively. ${ }^{18}$ No delayed aneurysm re-rupture was observed, meaning that WEB treatment effectively protects against rebleeding. Similar results were reported in the Clinical Assessment of WEB Device in Ruptured Aneurysms (CLARYS) study. ${ }^{19}$ The results of the USA and European studies also showed very similar efficacy at 1 year: complete aneurysm occlusion in $53.8 \%$ and $52.9 \%$, and adequate occlusion in $84.6 \%$ and $79.1 \%$, respectively. ${ }^{16}{ }^{17}$ In the USA series dedicated to ruptured aneurysms, aneurysm occlusion at 3 months was complete in $48.0 \%$ and adequate in $80.0 \% .{ }^{18}$ Finally, the efficacy of WEB aneurysm treatment was not only evaluated at 12 months, but also at 2 years and 3 years in the European studies, showing great stability of aneurysm occlusion after long term follow-up, with adequate occlusion in $81.0 \%$ and $83.6 \%$, respectively. ${ }^{20} 21$

\section{CONCLUSION}

Evaluating and discussing different EVT options available to treat WNBA requires scientific rigor, which means discussing published results in an unbiased manner, limiting the use of historical comparisons that have relatively low value, and building well designed studies that provide clear results regarding indications, feasibility, safety, and efficacy of given endovascular techniques.

Several endovascular techniques are currently available for the treatment of WNBAs, including coiling that very often in this situation requires balloon assistance, SAC, flow diversion, and intrasaccular flow disruption. Due to the great heterogeneity in populations treated in the series dealing with these different techniques, it is difficult to compare them adequately in terms of safety and efficacy. Currently, we do not have sufficient data to evaluate the safety of flow diversion in the EVT of WNBAs. Coiling (including BAC) and WEB treatment have similar safety, while SAC seems to be associated with a slightly higher rate of complications. In terms of efficacy, flow diversion studies in the global aneurysm population have shown high efficacy for this technique. Nonetheless, we still need to evaluate the subgroup of WNBAs to gain accurate results. With regard to SAC, the results are heterogeneous from one series to another, with adequate occlusion varying from $62.8 \%$ in the MAPS WNBA subgroup to $96.1 \%$ in the recent US pivotal trial. ${ }^{810}$ Finally, WEB aneurysm treatment is associated with good efficacy, with adequate occlusion at 1 year between $79.1 \%$ and $84.6 \% .^{1617}$

Even though these techniques are not competing with one another, they have similar indications. Currently, the need for DAPT in SAC and flow diversion limits their use to unruptured (or recanalized) intracranial aneurysms. Ruptured intracranial aneurysms may be treated at the acute phase of bleeding with these techniques if no other therapeutic alternative is possible. The development of coated stents and flow diverters will potentially change current therapies and techniques. ${ }^{22}$ Coiling (including BAC) and intrasaccular flow disruption are indicated in both unruptured and ruptured aneurysms. Further studies are needed to determine the precise and respective indications of different techniques not only according to aneurysm status, but also in relation to patient and aneurysm characteristics.

\section{Laurent Pierot $\odot{ }^{1}$ Laurent Spelle $\odot$, 2,3 Christophe Cognard, ${ }^{4}$ Istvan Szikora ${ }^{5}$}

${ }^{1}$ Neuroradiology, CHU Reims, Reims, ChampagneArdenne, France

${ }^{2}$ NEURI Interventional Neuroradiology, APHP, Paris, Île-de-France, France

${ }^{3}$ Paris-Saclay University Faculty of Medicine, Le KremlinBicetre, France

${ }^{4}$ Diagnostic and Therapeutic Neuroradiology, $\mathrm{CHU}$

Toulouse, Toulouse, Occitanie, France

${ }^{5}$ Neurointerventions, National Institute of Clinical

Neurosciences, Budapest, Budapest, Hungary

Correspondence to Dr Laurent Pierot, Neuroradiology, CHU Reims, Reims 51100, Champagne-Ardenne, France; Ipierot@gmail.com

Contributors All authors: have provided a substantial contribution to the conception and design of the studies and/or the acquisition and/or the analysis of the data, and/or the interpretation of the data; drafted the work or revised it for significant intellectual content; approved the final version of the manuscript; and agreed to be accountable for all aspects of the work, including its accuracy and integrity.

Funding The authors have not declared a specific grant for this research from any funding agency in the public, commercial, or not-for-profit sectors.

Competing interests $L P$ is a consultant for Balt, Microvention, Penumbra, Phenox, and Vesalio. LS is consultant for Medtronic, Microvention, and Balt, and receives a hospital research grant from Philips. CC is a consultant for Stryker, Microvention, Medtronic,
Cerenovus, and MIVI. IS is a consultant for Cerenovus, Medtronic, Stryker, and Microvention.

Patient consent for publication Not required.

Provenance and peer review Not commissioned; externally peer reviewed.

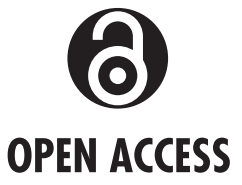

Open access This is an open access article distributed in accordance with the Creative Commons Attribution Non Commercial (CC BY-NC 4.0) license, which permits others to distribute, remix, adapt, build upon this work non-commercially, and license their derivative works on different terms, provided the original work is properly cited, appropriate credit is given, any changes made indicated, and the use is non-commercial. See: http:// creativecommons.org/licenses/by-nc/4.0/.

\section{Check for updates}

To cite Pierot L, Spelle L, Cognard C, et al. J Neurolntervent Surg 2021;13:e9.

Accepted 23 February 2021

J Neurolntervent Surg 2021;13:e9.

doi:10.1136/neurintsurg-2021-017459

\section{ORCID iDs}

Laurent Pierot http://orcid.org/0000-0002-6893-661X Laurent Spelle http://orcid.org/0000-0002-6748-8528 Istvan Szikora http://orcid.org/0000-0003-3730-3278

\section{REFERENCES}

1 Pierot L, Biondi A. Endovascular techniques for the management of wide-neck intracranial bifurcation aneurysms: a critical review of the literature. J Neuroradiol 2016;43:167-75.

2 Pierot L, Cognard C, Anxionnat R, et al. Endovascular treatment of ruptured intracranial aneurysms: factors affecting midterm quality anatomic results: analysis in a prospective, multicenter series of patients (CLARITY). AJNR Am J Neuroradiol 2012;33:1475-80.

3 Pierot L, Wakhloo AK. Endovascular treatment of intracranial aneurysms: current status. Stroke 2013:44:2046-54.

4 Pierot L, Cognard C, Spelle L, et al. Safety and efficacy of balloon remodeling technique during endovascular treatment of intracranial aneurysms: critical review of the literature. AJNR Am J Neuroradiol 2012;33:12-15.

5 Arat A, Cil B. Double-balloon remodeling of widenecked aneurysms distal to the circle of Willis. AJNR Am J Neuroradiol 2005;26:1768-71.

6 Fiorella D, Albuquerque FC, Deshmukh VR, et al. Usefulness of the Neuroform stent for the treatment of cerebral aneurysms: results at initial (3-6-mo) followup. Neurosurgery 2005;56:1191-202.

7 Hetts SW, Turk A, English JD, et al. Stent-assisted coiling versus coiling alone in unruptured intracranial aneurysms in the Matrix and Platinum Science trial: safety, efficacy, and mid-term outcomes. AJNR Am J Neuroradiol 2014;35:698-705.

8 Pranata R, Yonas E, Deka H, et al. Stent-assisted coiling of intracranial aneurysms using a nitinolbased stent (Neuroform Atlas): a systematic review and meta-analysis. Cardiovasc Intervent Radiol 2020;43:1049-61.

9 Fiorella D, Boulos A, Turk AS, et al. The safety and effectiveness of the LVIS stent system for the treatment of wide-necked cerebral aneurysms: final results of the pivotal us LVIS trial. J Neurointerv Surg 2019;11:357-61. 
10 Zaidat 00, Hanel RA, Sauvageau EA, et al. Pivotal trial of the Neuroform Atlas stent for treatment of anterior circulation aneurysms: one-year outcomes. Stroke 2020;51:2087-94.

11 Zhang X, Zuo Q, Tang H, et al. Stent assisted coiling versus non-stent assisted coiling for the management of ruptured intracranial aneurysms: a metaanalysis and systematic review. J Neurointerv Surg 2019;11:489-96.

12 Cagnazzo F, Limbucci N, Nappini S, et al. Y-stentassisted coiling of wide-neck bifurcation intracranial aneurysms: a meta-analysis. AJNR Am J Neuroradiol 2019:40:122-8.

13 Caroff J, Neki H, Mihalea C, et al. Flow-diverter stents for the treatment of saccular middle cerebral artery bifurcation aneurysms. AJNR Am J Neuroradiol 2016:37:279-84.

14 Michelozzi C, Darcourt J, Guenego A, et al. Flow diversion treatment of complex bifurcation aneurysms beyond the circle of Willis: complications, aneurysm sac occlusion, reabsorption, recurrence, and jailed branch modification at follow-up. J Neurosurg 2018;131:1751-62

15 Fiorella D, Molyneux A, Coon A, et al. Demographic, procedural and 30-day safety results from the WEB Intra-saccular Therapy Study (WEB-IT). J Neurointerv Surg 2017;9:1191-6.

16 Arthur AS, Molyneux A, Coon AL, et al. The safety and effectiveness of the Woven EndoBridge (WEB) system for the treatment of wide-necked bifurcation aneurysms: final 12-month results of the pivotal WEB Intrasaccular Therapy (WEB-IT) Study. J Neurointerv Surg 2019;11:924-30.

17 Pierot L, Moret J, Barreau X, et al. Safety and efficacy of aneurysm treatment with web in the cumulative population of three prospective, multicenter series. $J$ Neurointerv Surg 2018;10:553-9. Monteiro A, et al.

18 Cortez GM, Akture E, Monteiro A. Wowen Endobridge device for ruptured aneurysms: perioperative results of a US multicenter experience. J Neurolnterv/ Surg 2021:doi:10.1136/ neurintsurg-2020-017105. [Epub ahead of print 22 Jan 2021].

19 Spelle L, Herbreteau D, Barreau X, et al. CLARYS: clinical assessment of WEB device in ruptured aneurysms. Preliminary results. J Neuroradiol 2018;45:84-5.

20 Pierot L, Moret J, Barreau X, et al. Aneurysm treatment with WEB in the cumulative population of 3 prospective, multicenter series: 2-year follow-up. Neurosurgery 2020;87:357-67.

21 Pierot L, Szikora I, Barreau X, et al. Aneurysm treatment with web in the cumulative population of two prospective, multicenter series: 3-year follow-up. J Neurointerv Surg 2021;13:363-8.

22 Pierot L, Soize S, Cappucci M. Surface-Modified flow diverter p48-MW-HPC: preliminary clinical experience in 28 patients treated in two centers. J Neuroradiol 2020 